\title{
Rancangan pemilihan RT/RW pada sebuah lingkungan atau perumahan
}

\author{
Pradipta ricky baskara \\ TelkomUniversity; \\ Email: rickybas@telkomuniversity.ac.id
}

\begin{abstract}
Rukun Tetangga (RT) adalah pembagian wilayah di Indonesia di bawah Rukun Warga. Rukun Tetangga bukanlah termasuk pembagian administrasi pemerintahan, dan pembentukannya adalah melalui musyawarah masyarakat setempat dalam rangka pelayanan kemasyarakatan yang ditetapkan oleh Desa atau Kelurahan. Rukun Tetangga dipimpin oleh Ketua RT yang dipilih oleh warganya. Sebuah RT terdiri atas sejumlah rumah atau KK (kepala keluarga). Dalam sistem birokrasi di Indonesia, biasanya RT (Rukun Tetangga) berada di bawah RW (Rukun Warga). Sedangkan RT/RW biasanya memiliki masa jabatan aktif,jika masa jabatan aktif ini habis makan ada pergantian struktur RT/RW. Pergantian RT/RW ini dilakukan dengan cara voting oleh warga sekitar dan setelah voting maka akan di ambil voting tertinggi.
\end{abstract}

Paper ini akan dipublikasikan di osf.io [1] menggunakan format standard perancangan sistem informasi [2]

\section{Introduction}

\subsection{Business case}

Parete merupakan aplikasi berbasis mobile dimana aplikasi ini memudahkan warga warga yang menggunakan untuk voting pemilihan RT/RW di lingkungannya. Aplikasi ini juga memberikan informasi detail mengenai pemilihan RT/RW, sudah berapa warga yang ngevote dan sebagainya. Tujuan aplikasi ini adalah agar warga warga yang sibuk dengan aktivitasnya dapat menggunakan hak suaranya dengan baik dan bijak.

\subsection{System Requirement}

1. System Function Aplikasi PARETE merupakan aplikasi system informasi berbasis data yang memiliki fungsi sebagai berikut:

1. Mencatat dan mengumpulkan data dari pemilih

2. Menampilkan data data yang sudah memilih

3. Menampilkan laporan mengenai pemilihan RT/RW

2. System Feature

Aplikasi PARETE ini memiliki Fitur sebagai berikut

1. Aplikasi memiliki data informasi pemilih

2. Aplikasi memiliki data dari calon ketua

3. Aplikas memiliki data dari pemilih yang akan masuk ke database

3. System User Level

Aplikasi PARETE memiliki 3 tingkatan pengguna sebagai berikut :

1. Admin

Merupakan user dengan kedudukan paling tinggi dan memiliki wewenang untuk bertanggung jawab penuh mengelola aplikasi berjalan dengan baik

2. Pemilih Merupakan user warga yang telah mengisi data yang di daftarkan ke aplikasi

3. Calon Merupakan calon dari Ketua yang akan dipilih oleh warga setelah mendaftar ke aplikasi 


\section{Penjelasan SIngkat Terkait Metode}

Dalam pengembangan aplikasi ini, kami menggunakan metode Waterfall, dikarenakan metode ini relatif mudah dimengerti dan mudah digunakan. Waterfall menekankan pada sebuah desain proses yang berurutan yang dalam prosesnya terlihat seperti aliran air terjun dari proses perancangan konsep, analisis proyek, inisialisasi proyek, desain, pembuatan sistem, testing, implementasi dan perawatan.

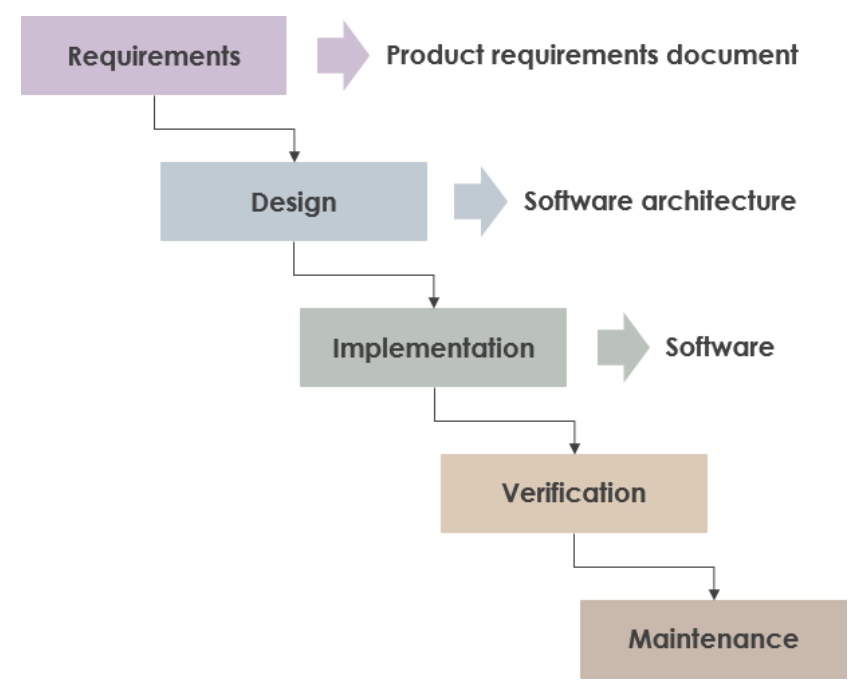

\section{Proses Perhitungan}

\subsection{System Design}

Tuliskan penjelasan di sini

\section{\#bubuhkan gambar atau tabel di sini bila diperlukan. Bila tidak diperlukan, silahkan dihapus saja}

Tabel 2. Contoh Penlisan Tabel

\begin{tabular}{ccc}
\hline Nama Kolom & Nama Kolom & Nama Kolom \\
\hline 1 & $\mathrm{~A}$ & $\mathrm{y}$ \\
2 & $\mathrm{~B}$ & $\mathrm{Yy}$ \\
3 & Bgfg & $\mathrm{Y}$ \\
4 & Rtrt & \\
5 & rtrt & $\mathrm{Yu}$ \\
\hline
\end{tabular}

3.2. Data Flow Diagram (DFD)

Tuliskan penjelasan di sini

DFD Level 0

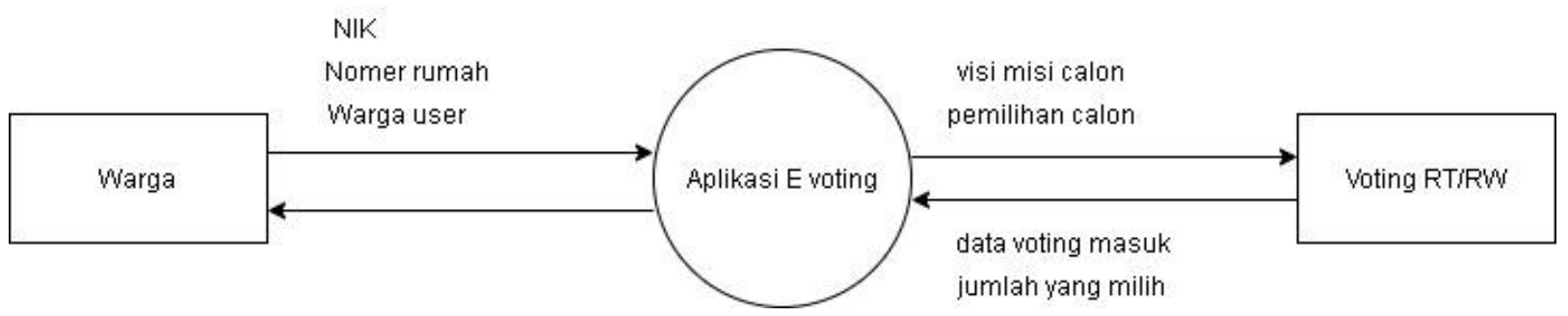



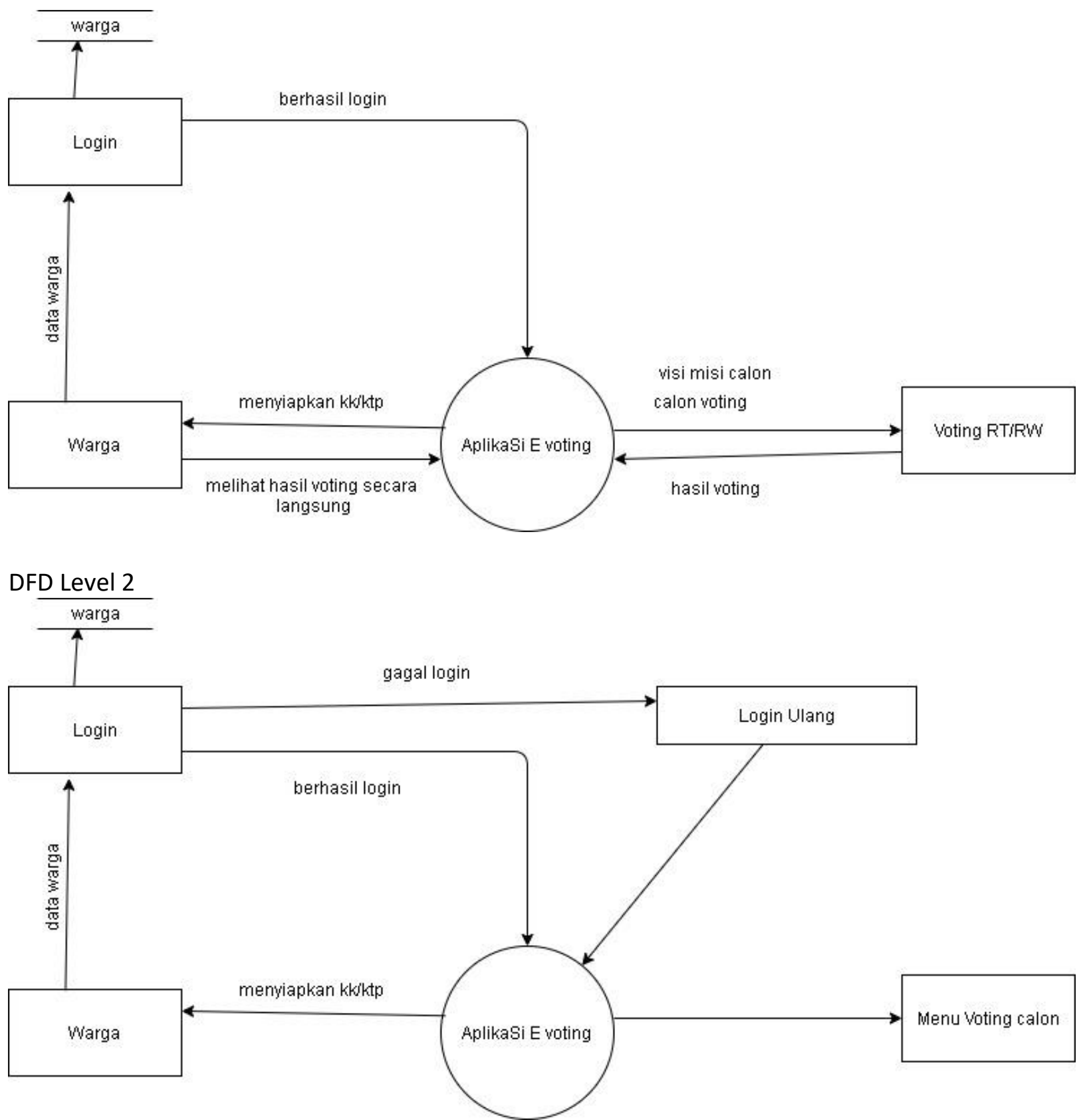

DFD Level 2

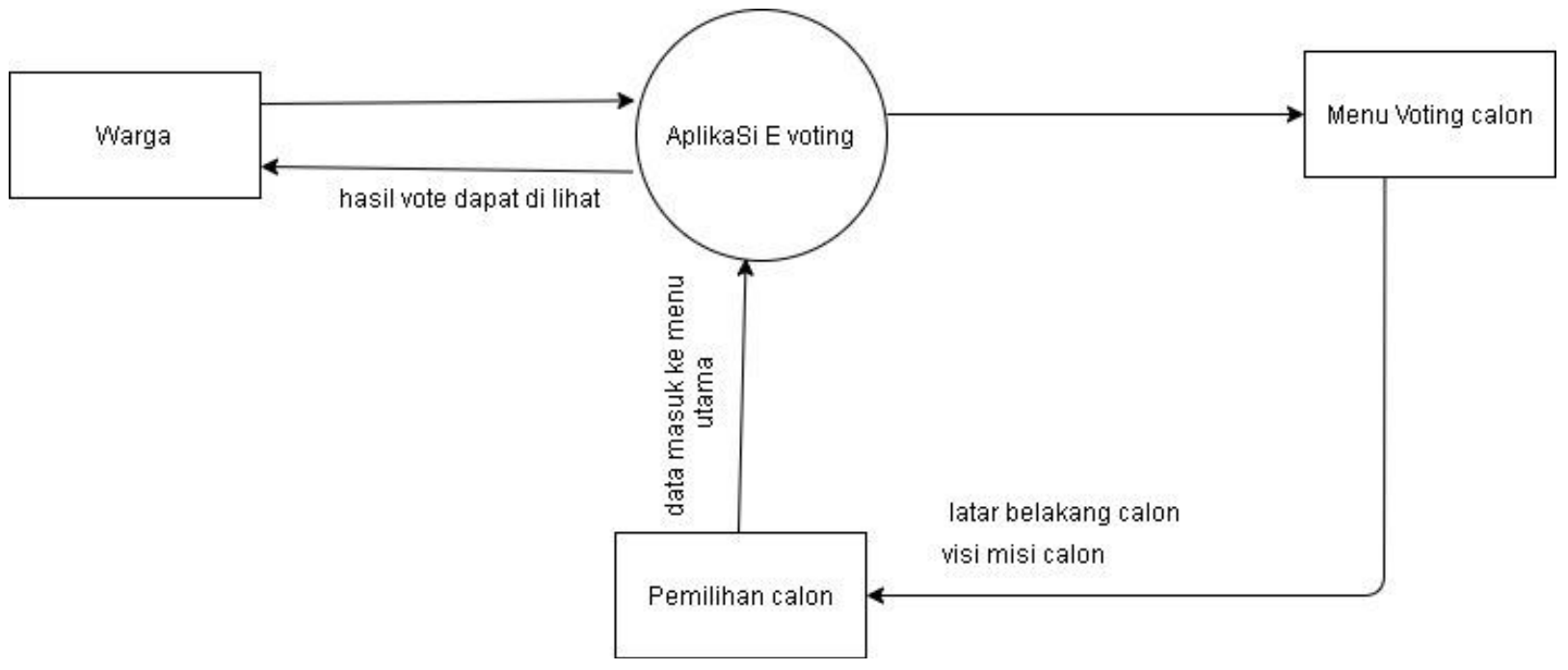




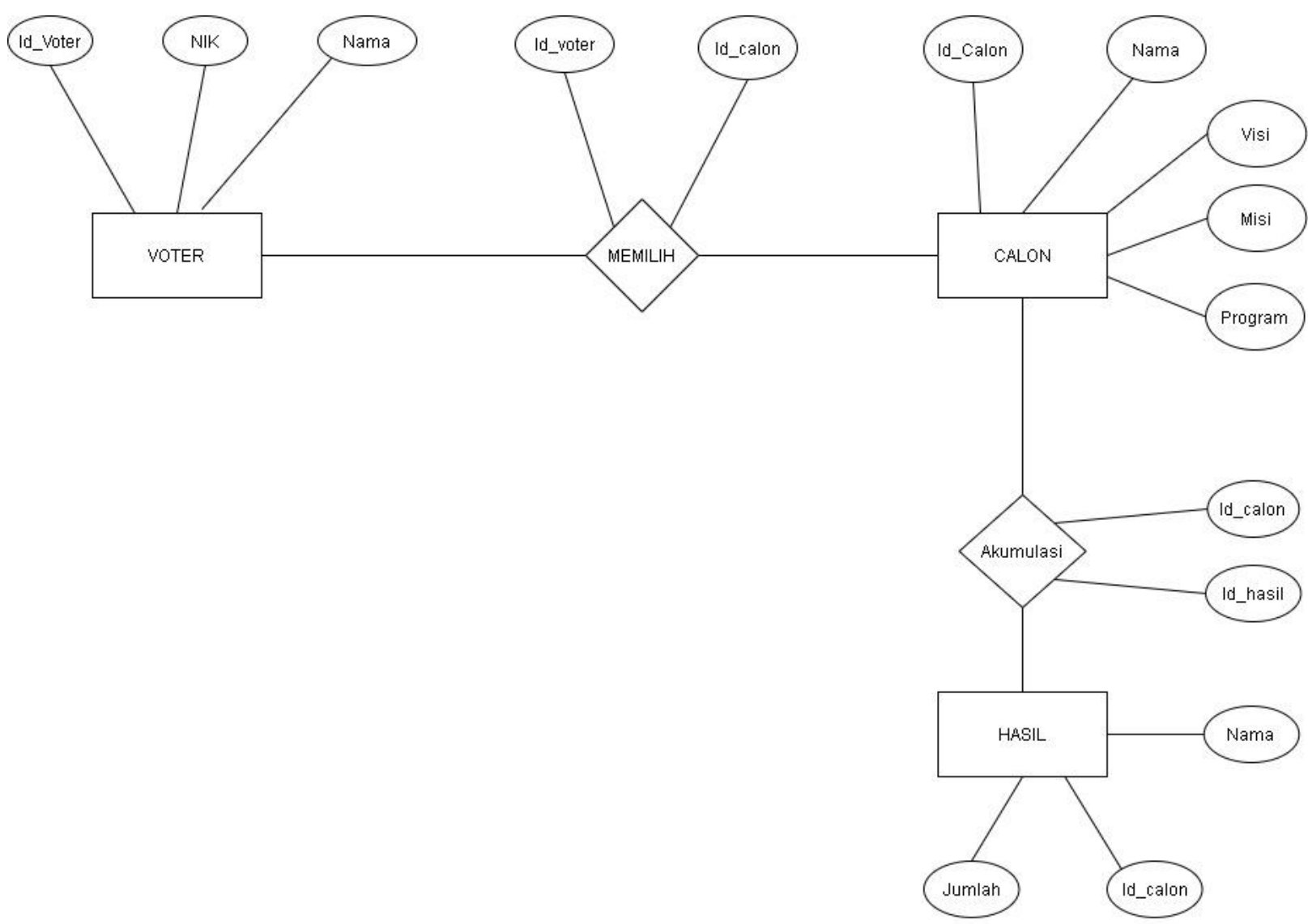

3.4. Database Design

Data Objects and File and Database Structures

3.5 Use Case Diagram

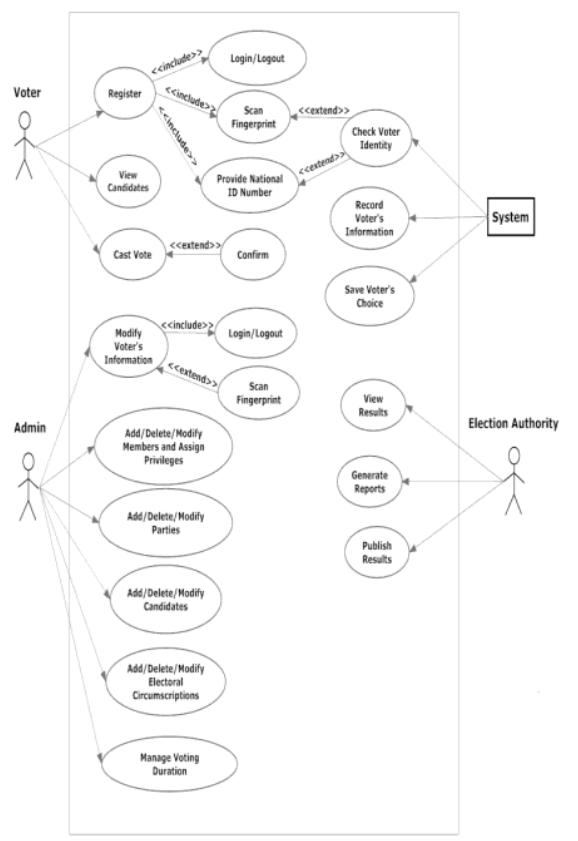


3.6 Activity Diagram

3.7 Sequence Diagram

\subsection{Interface Design}

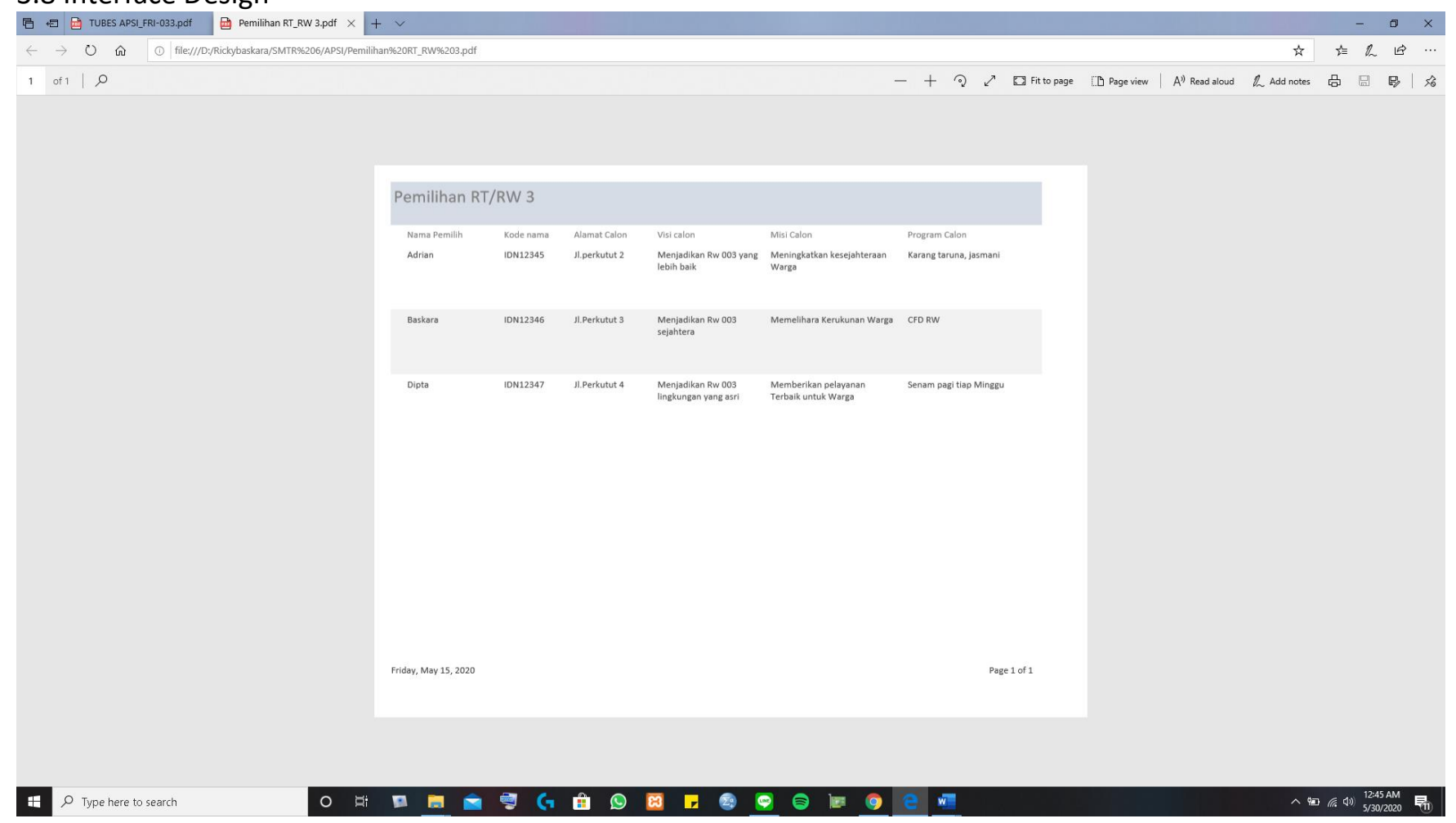

3.9 Source Code

\section{Penutup}

4.1 Kesimpulan

Aplikasi PARETE ini merupakan solusi bagi warganya yang sibuk akan aktivitas nya agar dapat memantau hasil pemilihan dan dapat memilih di mana pun dan kapan pun. Aplikasi ini juga dapat mencatat data data yang masuk dan dapat menghitung suara dengan akurat dan cepat tanpa harus menunggu orang menghitungnya. Para pemilih pun juga dapat mengetahui jumlah suara yang masuk dan suara yang tidak terhitung.

4.2 Saran

Untuk aplikasi masih dalam tahap pengembangan agar aplikasi ini tidak down ketika banyak pengguna yang menggunakan aplikasi tersebut

\section{References}


[1] R. Aurachman, "Review Terhadap OSF.IO Sebagai Sarana Publikasi Preprint," OSF Preprints, 17 May 2020.

[2] R. Aurachman, "Kerangka Perancangan Sistem Informasi Sebagai Pembelajaran Mahasiswa Teknik Industri," osf.io, 52020.

\section{Additional}

[a] R. Aurachman, "Review Terhadap OSF.IO Sebagai Sarana Publikasi Preprint," OSF Preprints, 17 May 2020. doi:10.31219/osf.io/rvumx , Available: https://osf.io rvumx

[b] R. Aurachman, "Kerangka Perancangan Sistem Informasi Sebagai Pembelajaran Mahasiswa Teknik Industri," osf.io, doi:10.31219/osf.io/tmpcn , 5 2020. Available: https://osf.io/tmpcn 